\title{
The effects of age and task context on Stroop task performance
}

\author{
SHARON A. MUTTER, JENNIFER C. NAYLOR, and EMILY R. PATTERSON \\ Western Kentucky University, Bowling Green, Kentucky
}

\begin{abstract}
In this study, we investigated the impact of age and task context on Stroop task performance, using error scores, response latencies, and process dissociation estimates (e.g., Lindsay \& Jacoby, 1994). Across three experiments, the findings showed that although older adults were able to evaluate Stroop task demands and modify their representations of task context in response to this knowledge, they were less able to maintain and update these representations on a trial-by-trial basis in tasks with high stimulus uncertainty or ambiguity. Moreover, although there was no age-related decline in the ability to modulate print color information, older adults were consistently less able to control the activation of conflicting word information. Together, these findings suggest that whereas age differences in the Stroop task may be magnified under conditions that promote transient failures to maintain task context, the primary source of these differences seems to be a more enduring decline in the efficiency of processes that are responsible for suppressing the activation of irrelevant lexical information.
\end{abstract}

In 1935, J. R. Stroop observed that people sometimes have trouble attending to one dimension of a stimulus while ignoring another irrelevant dimension. Since that time, hundreds of studies on the Stroop effect have been conducted. In a typical Stroop task, participants are shown color words that are printed in various colors and are asked to identify, as quickly as possible, the print color of the words. Skilled readers have greater difficulty with this task when word meaning and print color are incongruent (e.g., the word green printed in red ink) than when word meaning and print color are congruent (e.g., the word green printed in green ink; for a review, see MacLeod, 1991). Two components of the Stroop effect, interference and facilitation, can be distinguished by comparing performance in the incongruent and congruent color word conditions with performance in a baseline condition employing colored stimuli that are not color words (e.g., neutral words, nonwords, nonlexical symbols, or color patches). Interference occurs when response latencies are longer in the incongruent condition than in the baseline condition; facilitation occurs when latencies are shorter in the congruent condition than in the baseline condition.

As compared with younger adults, adults over the age of 60 consistently experience greater interference in the

Preliminary reports on parts of this research were presented at the 38th Annual Meeting of the Psychonomic Society, Philadelphia, November 1997, and at the Tenth Annual Meeting of Cognitive Aging Conference, Atlanta, April 2000. We thank Steven Haggbloom for his helpful comments on a draft of this article, and we are grateful to Kelly Goedert and Tommy Williams for their assistance with participant recruitment and scheduling. Jennifer Naylor is now at the Department of Medical Psychiatry, Duke University, Durham, NC. Correspondence should be addressed to S. A. Mutter, Department of Psychology, Western Kentucky University, 1 Big Red Way, Bowling Green, KY 42104 (e-mail: sharon.mutter@wku.edu).
Stroop task (see, e.g., Cohn, Dustman, \& Bradford, 1984; Comalli, Wapner, \& Werner, 1962; Houx, Jolles, \& Vreeling, 1993; Spieler, Balota, \& Faust, 1996) and occasionally experience greater facilitation (e.g., West \& Baylis, 1998), suggesting that older adults are less able to ignore the irrelevant word dimension. Moreover, whereas younger adults are able to vary the degree of control that they exert over word reading in response to Stroop task demands (Logan \& Zbrodoff, 1979; Logan, Zbrodoff, \& Williamson, 1984), older adults may be less able to do so (Dulaney \& Rogers, 1994; West \& Baylis, 1998). The purpose of the present study was to obtain additional information on the extent of these age-related changes in the Stroop task.

One of the most compelling theoretical accounts of the Stroop effect is that activation of irrelevant word name information occurs automatically for skilled readers, whereas activation of relevant print color information requires greater attentional resources. As a result, word name information interferes with print color information and must be filtered or suppressed for successful performance (Posner \& Snyder, 1975). However, this simple automaticity explanation has been challenged in recent years by several findings suggesting that attentional processes can control the magnitude of interference effects. First, developmental variations in interference are contrary to what would be predicted by the automaticity model (Dulaney \& Rogers, 1994). Interference in the Stroop task declines from childhood to young adulthood, despite increased automaticity of reading (see MacLeod, 1991), but then increases again in old age (e.g., Cohn et al., 1984; Comalli et al., 1962; Houx et al., 1993; Spieler et al., 1996; West \& Baylis, 1998). This pattern of findings suggests that control over interfering word name information improves into adulthood, then declines with increasing age. 
A second source of evidence against the simple automaticity view comes from findings that task context can have a large impact on Stroop interference (MacLeod, 1991). Several studies have shown that interference effects can be reduced by introducing variations into the Stroop task that induce participants to more narrowly focus their attention on print color. For example, spatially separating the conflicting color word name and print color dimensions (Kahneman \& Henik, 1981), coloring only a single letter in a color target word (Besner, Stolz, \& Boutilier, 1997), and precuing a single letter position in a wholely colored target word (Besner \& Stolz, 1999) all reduce interference. Likewise, Logan and his colleagues (Logan et al., 1984; see also Cheesman \& Merikle, 1986, and Lowe \& Mitterer, 1982, for similar findings) have shown that the proportion of incongruent versus congruent trials in a list affects the magnitude of interference. They found a strong interference effect for a list containing $80 \%$ congruent trials, but not for a list containing $80 \%$ incongruent trials. This outcome suggests that participants represent the task context differently in these two conditions (Logan \& Zbrodoff, 1979; Logan et al., 1984). When a list is composed of a high proportion of congruent trials, participants recognize that failure to maintain the goal of identifying print color will have little cost and that exerting sustained control over word reading is not necessary, because word name rarely competes with print color. However, when the proportion of incongruent trials is high, participants recognize that failure to maintain the task goal will have substantial costs and, further, that sustained control over word reading is necessary to prevent word name information from competing with print color information.

In line with these findings, recent models of the Stroop effect include a mechanism by which task context can influence the degree of activation of both print color information and word name information. For example, in Cohen, Dunbar, and McClelland's (1990) parallel distributed processing model, presentation of a Stroop word activates processing units representing the word name, as well as units representing the print color. Activation along pathways from these processing units to units representing the response can be tuned or modulated by input from separate units representing the task context, where context can include any task-relevant information, such as instructions, intended goals and actions, and expectancies resulting from the processing of prior task stimuli (Braver et al., 2001). Task context units are instrumental both in suppressing activation of habitual or automatic word-reading responses and in maintaining activation of task-relevant color-naming responses. If these units are underactive (i.e., context is poorly represented), wordreading, rather than color-naming, responses will dominate behavior.

This model of the Stroop effect is consistent with current theories of working memory (WM) that include a supervisory attentional component. This component of WM serves to select and maintain activation of task-relevant goals and information, to suppress or prevent entry of task-irrelevant information, to recognize and resolve conflicts between competing sources of information, and to monitor errors (e.g., Baddeley \& Hitch, 1974; Kane \& Engle, 2003; Shallice \& Burgess, 1993). Researchers have recently begun to examine the issue of whether the operation of the supervisory attentional system in the Stroop task is less efficient in older adults and in other individuals with WM capacity limitations. In one of the first studies to address the impact of WM on attentional processes in the Stroop task, Long and Prat (2002) gave younger adults with high and low WM spans lists with different proportions of incongruent trials. As was noted previously, younger adults modify their representations of the task context in response to this manipulation, resulting in less interference for lists with higher proportions of incongruent trials (Logan \& Zbrodoff, 1979; Logan et al., 1984). Long and Prat replicated this finding for individuals with high WM spans but found that younger adults with low spans suffered substantial interference effects, regardless of list composition. In a similar vein, West and Baylis (1998) reported that age differences in interference were greater for a list composed of proportionally more incongruent trials than congruent trials. These studies suggest that the greater interference shown by older adults and other individuals with reduced WM capacity is due to a decline in their ability to develop and/or maintain effective representations of the Stroop task context (for a discussion of how impaired context processing may be responsible for age-related decline in other cognitive tasks, see Braver et al., 2001).

Findings from a recent study by Kane and Engle (2003) suggest that this issue is more complex. In their study, individuals with low WM spans showed greater interference effects than did those with high spans, regardless of list congruency proportion. Low-span individuals also made more word reading errors than did high-span individuals, for lists containing high proportions of congruent trials. However, low-span individuals did not have inflated word-reading errors for mostly incongruent lists, nor did they have inflated error rates for mostly congruent lists after practice with a mostly incongruent list. These findings suggest that two independent processes contribute to Stroop interference in individuals with low WM spans. First, they are more likely to suffer transient failures in maintaining a representation of task context unless the task environment provides some support for this process, and second, they are consistently less efficient at resolving the response conflict created by habitual activation of irrelevant word information.

In the present study, we explored age differences in the representation of Stroop task context by manipulating the proportion of congruent to incongruent trials. If older adults suffer a general decline in the ability to accurately represent different task contexts, interference effects in their responses should not vary as a function of the proportion of congruent and incongruent trials, and age differences in these effects should be greatest when maintenance of the context is most critical (e.g., high proportion of incongruent trials; cf. West \& Baylis, 1998). We also 
examined whether this same pattern would be present in older adults' word-reading intrusions, because this measure provides a sensitive measure of the maintenance of task context (Kane \& Engle, 2003). Finally, we examined process dissociation estimates of adults' color-naming and word-reading processes. Current models of the Stroop effect (Cohen et al., 1990) suggest that task context modulates the activation of both color and word information. It is unknown, however, how age affects context-related modulation of these two sources of influence on the Stroop response. The standard response time analysis of interference and facilitation does not allow us to examine the separate contributions of color naming and word reading to a response in the Stroop task. We therefore used the Stroop process dissociation (PD) analysis developed by Lindsay and Jacoby (1994) to obtain estimates of the influence of these two processes on younger and older adults' responses in the different task contexts.

The Stroop PD analysis is based on the logic that an accurate response on a congruent trial can be made using either color naming or word reading, whereas an accurate response on an incongruent trial can only be made using color naming. The influence of word-reading and colornaming processes on responding during the Stroop task can be estimated by simultaneously solving the following equations: $p$ (correct/congruent $)=$ Word + Color $(1-$ Word $)$ and $p$ (correct/incongruent $)=$ Color $(1-$ Word $) .{ }^{1}$ Because the Stroop PD analysis is based on response accuracy in congruent and incongruent trials, rather than on response latency, it also offers a way to avoid problems associated with measuring the influence of wordreading processes in terms of differences from a neutral baseline (Lindsay \& Jacoby, 1994). The size of interference effects can depend on the type of neutral stimuli (e.g., strings of symbols, colored patches, nonwords, or noncolor words) used to obtain a baseline measure of color-naming latency (MacLeod, 1991). Moreover, the degree of interference produced by neutral stimuli may vary with age (Spieler et al., 1996).

As far as we know, only one other study has used Stroop PD to examine older adults' Stroop performance. Spieler et al. (1996) obtained estimates of color-naming and word-reading processes for younger and older adults in the standard Stroop task (i.e., 50\% congruent and 50\% incongruent trials) and found that whereas estimates for the color-naming process did not vary with age, estimates for the word-reading process were higher for older adults than for younger adults. This finding suggests that age differences in Stroop interference are due to older adults' difficulty in suppressing irrelevant word name information. However, this earlier study did not examine how PD estimates for younger and older adults vary in response to task context. Lindsay and Jacoby (1994) have shown that increasing the proportion of incongruent to congruent trials reduces estimates of the wordreading process in younger adults' Stroop responses but has little effect on estimates of the color-naming process. This suggests that their younger participants responded to the more demanding list by establishing a task context that emphasized greater control over word reading. If older adults do not respond in the same way, there should be little difference in their word-reading process estimates for lists with different proportions of congruent and incongruent trials. It will also be possible to examine whether this manipulation has differential effects on younger and older adults' color-naming process estimates. Despite earlier findings to the contrary (Lindsay \& Jacoby, 1994), models of the Stroop effect (Cohen et al., 1990), as well as neuropsychological evidence (e.g., Corbetta, Miezin, Dobmeyer, Shulman, \& Petersen, 1990; West \& Alain, 2000b), suggest that individuals should be able to boost activation of print color information when the cost of not doing so is high. If older adults are less able to do this, their color-naming estimates may be lower than those of younger adults, especially in lists with higher proportions of incongruent items.

\section{EXPERIMENT 1}

The purpose of this preliminary experiment was to determine whether the color-naming and word-reading PD estimates obtained for younger and older adults on a standard Stroop task would be consistent with those reported by Spieler et al. (1996), despite the use of somewhat different procedures. Procedural variations across the two studies included differences in the stimulus-timing characteristics, the type of neutral stimuli, the overall number of congruent, incongruent, and neutral trials, and the response-recording method.

\section{Method}

Participants. The procedures used for recruiting participants, providing incentives for participation, screening for color blindness, and collecting data on demographic characteristics, health history, and basic cognitive functioning were the same across all three experiments reported in this article. Younger participants were recruited from introductory psychology classes at Western Kentucky University and received extra credit in their class for participating in the experiment. Older participants were recruited from the community and were paid a small stipend for participating. All the participants were screened for colorblindness, using Ishihara's Tests for Colour-Blindness (Ishihara, 1994), and all completed a survey with questions about their demographic characteristics and health history. Across the three experiments, 1 younger adult failed the color blindness test and was replaced. None of the participants reported histories of neurological or psychiatric illness, and none was taking medications known to affect cognitive functioning. All were in good health for their respective age group. The participants were also given tests of basic cognitive ability, including the Digit Span and Vocabulary subtests of the WAIS-R (Wechsler, 1981), the FAS Verbal Fluency Task (Benton \& Hamsher, 1989), and the Reading Span Task (Salthouse \& Babcock, 1991).

Twelve younger adults between the ages of 18 and 30 years $(M=$ 20.92 years, $S D=2.78$ ) and 12 older adults 60 years and above in age $(M=70.5$ years, $S D=4.68)$ participated in this experiment. Demographic information for these participants and their scores on the tests of basic cognitive functioning are presented in Table 1.

Materials and Design. The design was a 2 (age: younger vs. older) $\times 3$ (trial type: congruent vs. neutral vs. incongruent) mixed factorial, with age as a between-subjects variable and trial type as a within-subjects variable. Dependent variables included latency to name the print color of a stimulus item and the proportion of correct naming responses. Latency measures were used to determine 
Stroop interference and facilitation effects; accuracy measures were used in the PD analysis to estimate the influence of word-reading and color-naming processes on Stroop performance.

A Power Macintosh computer with a color monitor, running MacLaboratory for Psychology (Version 3.0.2) software, controlled stimulus display and data collection. Stimuli for the congruent and incongruent trials were the words blue, green, orange, red, and yellow; the stimulus for the neutral trials was a string of five percentage signs $(\% \% \% \% \%)$. These stimuli were presented in the center of the monitor screen in a 24-point Helvetica font in blue, green, orange, red, or yellow print against a light gray background. The 100trial test list consisted of 40 congruent trials, 40 incongruent trials, and 20 neutral trials. The set of congruent trials consisted of the five color words presented eight times each in their matching print colors, the set of incongruent trials consisted of the five color words presented twice in each of the four nonmatching print colors, and the set of neutral trials consisted of the string of percentage signs presented four times in each of the five print colors. A 40-trial practice list with the same proportion of congruent, incongruent, and neutral trials as on the test list was also constructed; however, not all word name and print color combinations were included in this list. In both the practice and the test lists, congruent, incongruent, and neutral stimuli were randomly assigned to list positions, with the constraints that stimuli with the same print color did not appear in successive trials and that the print color of a stimulus was not the same as the color name of the stimulus in the preceding trial.

Procedure. The participants were tested individually in a session lasting approximately $1.5 \mathrm{~h}$. At the beginning of the session, the participants completed informed consent procedures, the questionnaire on demographic characteristics and health status, and the color blindness screening. After these preliminary procedures, they were seated in front of the monitor and were given instructions for the Stroop task. They were told that they would see a mixed list of

Table 1

Participant Characteristics for Experiments 1, 2, and 3

\begin{tabular}{|c|c|c|c|c|c|}
\hline \multirow[b]{3}{*}{ Measure } & \multicolumn{4}{|c|}{ Age Group } & \multirow[b]{3}{*}{ Effect } \\
\hline & \multicolumn{2}{|c|}{ Younger } & \multicolumn{2}{|c|}{ Older } & \\
\hline & $M$ & $S D$ & $M$ & $S D$ & \\
\hline \multicolumn{6}{|c|}{ Experiment 1} \\
\hline Education $^{\mathrm{a}}$ & 14.08 & 1.83 & 14.42 & 1.56 & n.s. \\
\hline FAS & 39.83 & 8.82 & 34.72 & 12.25 & n.s. \\
\hline Reading span & 2.50 & 0.67 & 1.33 & 0.65 & ${ }^{* *}$ \\
\hline Digit span ${ }^{\mathrm{b}}$ & 15.58 & 3.58 & 14.33 & 3.50 & n.s. \\
\hline Vocabulary & 44.58 & 10.91 & 51.67 & 7.92 & n.s. \\
\hline \multicolumn{6}{|c|}{ Experiment 2} \\
\hline Education ${ }^{\mathrm{a}}$ & 15.00 & 1.50 & 15.71 & 1.94 & n.s. \\
\hline FAS & 41.92 & 9.32 & 34.20 & 9.57 & ${ }^{* *}$ \\
\hline Reading span & 2.54 & 1.06 & 1.87 & 0.89 & * \\
\hline Digit span ${ }^{a}$ & 16.96 & 4.79 & 14.37 & 3.32 & * \\
\hline Vocabularyc & 46.83 & 11.34 & 52.17 & 6.12 & * \\
\hline \multicolumn{6}{|c|}{ Experiment 3} \\
\hline Education $^{\mathrm{a}}$ & 13.08 & 1.52 & 15.31 & 2.71 & ** \\
\hline FAS & 38.45 & 8.97 & 38.10 & 10.31 & n.s. \\
\hline Reading span & 2.07 & 0.82 & 1.70 & 0.96 & * \\
\hline Digit span ${ }^{\mathrm{b}}$ & 7.75 & 2.30 & 6.45 & 2.01 & ** \\
\hline Vocabularyc & 34.28 & 6.03 & 47.49 & 11.95 & ** \\
\hline Digit symbol & 85.23 & 11.77 & 55.97 & 15.40 & ** \\
\hline
\end{tabular}

aNumber of years completed. ${ }^{b}$ WAIS-R Forward and Backward Digit Span subtests were administered in Experiments 1 and 2, whereas only the Backward Digit Span subtest was administered in Experiment 3. cThe WAIS-R Vocabulary subtest was administered in Experiments 1 and 2, whereas the Mill Hill Vocabulary test was administered in Experiment $3 . \quad{ }^{*} p \leq .05 . \quad{ }^{* *} p \leq .01$. color words and percentage signs presented one by one on the screen and that they should try to name the print color of the item as quickly as possible and before the occurrence of a warning signal. The participants completed the practice trials first and were given feedback on their performance and a reminder to respond before the warning signal. They then completed the test trials and the tests of basic cognitive ability.

For both the practice and the test trials, the stimuli appeared on the screen either until the participant responded or for a duration of $1,200 \mathrm{msec}$ for younger adults and $1,500 \mathrm{msec}$ for older adults. A 25 -msec tone occurred if a response was not made within $775 \mathrm{msec}$ for the younger participants and $850 \mathrm{msec}$ for the older participants (see Lindsay \& Jacoby, 1994). ${ }^{2}$ A blank gray screen, which remained in view for $2,000 \mathrm{msec}$, intervened between the participant's response and the next trial. As soon as the participant vocalized a response for an item, the experimenter pressed a key on the keyboard to record the response latency, and the response was recorded on audiotape for later accuracy coding. The experimenter could not see the stimuli appearing on the screen. One advantage of using this procedure is that participants are not required to learn the mapping of color responses to particular response keys, thus allowing us to use a greater number of color responses; a second advantage is that it minimizes the loss of data that can occur when nonresponse noise triggers a voice key or when a response is not detected. These advantages are particularly important in aging research. On the other hand, the procedure can introduce additional error variance into the response time measure. We attempted to minimize this problem by using the same experimenter throughout the experiments and by ensuring that the experimenter was unable to anticipate the trial type or the print color of the stimuli. Some evidence of success in this regard is provided by the fact that our means and standard deviations for congruent, incongruent, and neutral trial latencies are in the same range as those obtained in studies that employed a response (e.g., West \& Baylis, 1998) or a voice key (e.g., Spieler et al., 1996) and our data show the same general pattern.

\section{Results and Discussion}

Unless otherwise noted, tests for all three experiments reported here were conducted using an alpha of $p \leq .05$. Trials with incorrect responses were excluded from the analyses of response latency and were analyzed separately. In addition, outliers were eliminated by removing correct trials with response latencies that were less than or greater than three standard deviations from a participant's mean for the respective trial type. This resulted in the elimination of no more than $0.6 \%-1.4 \%$ of the responses for both the younger and the older adults in any of the conditions in the three experiments.

Intrusion errors and response latencies. Error rates for the younger and older participants for the congruent, incongruent, and neutral trials are shown in Table 2. Error analyses were conducted only on errors for the incongruent trials. These errors were, without exception, intrusion errors, whereas it was not possible to determine whether errors for the congruent trials were from color naming or word reading. A one-way analysis of variance (ANOVA) for the effect of age on arcsine-transformed error rates for incongruent trials revealed a main effect of age $\left[F(1,22)=4.18, M S_{\mathrm{e}}=0.10, \eta^{2}=.16\right]$, showing that the older adults responded with the conflicting word more often than did the younger adults.

Mean response times for the congruent, incongruent, and control trials are shown in Table 2. The effect of age 
Table 2

Means and Standard Deviations for Color Naming Latencies (in Milliseconds), Proportions of Errors, and Interference and Facilitation Scores for Younger and Older Participants in Experiments 1, 2, and 3

\begin{tabular}{|c|c|c|c|c|c|c|c|c|c|c|c|c|c|c|c|c|}
\hline \multirow[b]{4}{*}{ Participants } & \multicolumn{12}{|c|}{ Trial Type } & & & & \\
\hline & \multicolumn{4}{|c|}{ Congruent } & \multicolumn{4}{|c|}{ Incongruent } & \multicolumn{4}{|c|}{ Neutral } & \multicolumn{4}{|c|}{ Score* $^{*}$} \\
\hline & \multicolumn{2}{|c|}{ RT } & \multicolumn{2}{|c|}{ Errors } & \multicolumn{2}{|c|}{ RT } & \multicolumn{2}{|c|}{ Errors } & \multicolumn{2}{|c|}{ RT } & \multicolumn{2}{|c|}{ Errors } & \multicolumn{2}{|c|}{ Interference } & \multicolumn{2}{|c|}{ Facilitation } \\
\hline & $M$ & $S D$ & $M$ & $S D$ & $M$ & $S D$ & $M$ & $S D$ & $M$ & $S D$ & $M$ & $S D$ & $M$ & $S D$ & $M$ & $S D$ \\
\hline \multicolumn{17}{|c|}{ Experiment 1} \\
\hline Younger & 688 & 50 & .01 & .02 & 794 & 66 & .12 & .08 & 710 & 45 & .02 & .03 & 84 & 31 & 22 & 18 \\
\hline Older & 771 & 107 & .01 & .01 & 955 & 115 & .21 & .14 & 835 & 90 & .05 & .06 & 120 & 51 & 64 & 39 \\
\hline \multicolumn{17}{|c|}{ Experiment 2} \\
\hline \multicolumn{17}{|l|}{ Mostly congruent } \\
\hline Younger & 642 & 36 & .00 & .00 & 849 & 105 & .43 & .19 & 720 & 40 & .00 & .01 & 130 & 78 & 77 & 34 \\
\hline Older & 729 & 71 & .00 & .00 & 1,014 & 90 & .40 & .23 & 841 & 74 & .03 & .06 & 172 & 70 & 112 & 64 \\
\hline \multicolumn{17}{|c|}{ Mostly incongruent } \\
\hline Younger & 711 & 55 & .02 & .05 & 781 & 64 & .08 & .04 & 731 & 45 & .03 & .05 & 50 & 29 & 20 & 37 \\
\hline Older & 859 & 107 & .01 & .02 & 971 & 88 & .14 & .11 & 875 & 84 & .03 & .05 & 96 & 33 & 17 & 66 \\
\hline \multicolumn{17}{|c|}{ Experiment 3} \\
\hline \multicolumn{17}{|l|}{$100 \mathrm{C} / 0 \mathrm{I}$} \\
\hline Younger & 535 & 45 & .01 & .01 & - & - & 580 & 45 & .01 & .01 & - & 45 & 24 & & & \\
\hline \multirow{2}{*}{\multicolumn{17}{|c|}{$75 \mathrm{C} / 25 \mathrm{I}$}} \\
\hline & & & & & & & & & & & & & & & & \\
\hline Younger & 578 & 64 & .01 & .01 & 637 & 86 & .02 & .04 & 607 & 58 & .02 & .03 & 30 & 46 & 29 & 17 \\
\hline Older & 669 & 58 & .01 & .01 & 782 & 75 & .03 & .03 & 724 & 70 & .01 & .01 & 58 & 45 & 55 & 33 \\
\hline \multicolumn{17}{|l|}{$50 \mathrm{C} / 50 \mathrm{I}$} \\
\hline Younger & 620 & 59 & .01 & .01 & 679 & 54 & .01 & .01 & 642 & 52 & .01 & .01 & 37 & 18 & 22 & 14 \\
\hline Older & 677 & 71 & .02 & .02 & 774 & 88 & .03 & .02 & 699 & 86 & .02 & .02 & 75 & 24 & 22 & 36 \\
\hline \multicolumn{17}{|l|}{$25 \mathrm{C} / 75 \mathrm{I}$} \\
\hline Younger & 582 & 71 & .01 & .01 & 637 & 75 & .02 & .02 & 612 & 75 & .01 & .01 & 26 & 15 & 29 & 18 \\
\hline Older & 645 & 95 & .01 & .01 & 711 & 100 & .02 & .02 & 667 & 77 & .01 & .01 & 44 & 30 & 22 & .28 \\
\hline \multicolumn{17}{|l|}{$0 \mathrm{C} / 100 \mathrm{I}$} \\
\hline Younger & - & - & 666 & 74 & .02 & .01 & 647 & 69 & .00 & .01 & 20 & 16 & - & & & \\
\hline Older & - & - & 781 & 112 & .03 & .02 & 736 & 117 & .01 & .01 & 45 & 22 & - & & & \\
\hline
\end{tabular}

*Interference score $=$ incongruent - neutral; facilitation score $=$ neutral - congruent.

on facilitation was examined with a 2 (age: younger vs. older) $\times 2$ (trial type: congruent vs. neutral) mixed factorial ANOVA. A main effect of trial type $[F(1,22)=$ $\left.49.59, M S_{\mathrm{e}}=457.02, \eta^{2}=.69\right]$ indicated that responses were faster for the congruent than for the neutral trials. In addition, there was an age $\times$ trial type interaction $\left[F(1,22)=11.63, \eta^{2}=.35\right]$, showing that facilitation was greater for the older adults than for the younger adults. A 2 (age: younger vs. older) $\times 2$ (trial type: incongruent vs. neutral) mixed factorial ANOVA for the effect of age on interference revealed a main effect of trial type $[F(1,22)=$ $\left.141.25, M S_{\mathrm{e}}=878.14, \eta^{2}=.87\right]$, reflecting the slower responses for the incongruent trials than for the neutral trials. This overall interference effect was qualified by an age $\times$ trial type interaction $\left[F(1,22)=4.49, M S_{\mathrm{e}}=878.14, \eta^{2}=\right.$ .17 ], showing that interference was greater for the older than for the younger adults. ${ }^{3}$

The age differences in word-reading errors show that the older adults were more likely than the younger adults to suffer occasional failures to maintain the task goal of identifying the print color and ignoring the word. Moreover, their higher facilitation scores suggest that they benefited from these relatively quick error responses on the congruent trials (see MacLeod \& MacDonald, 2000, for a discussion of the relation between word-reading er- rors and facilitation). The age differences in interference suggest that the older adults also took longer to resolve the conflict between the irrelevant word information and the relevant color information. These findings are thus consistent with a large body of research on aging effects in the Stroop task (e.g., Cohn et al., 1984; Comalli et al., 1962; Houx et al., 1993; Spieler et al., 1996, West \& Baylis, 1998).

Process dissociation estimates. Using the method developed by Lindsay and Jacoby (1994), the estimated contributions of color-naming and word-reading processes to Stroop task performance were obtained for nine post hoc deadlines ranging from 600 to $1,400 \mathrm{msec}$ in $100-\mathrm{msec}$ increments. For each participant, the proportion of correct responses within each deadline was obtained for the congruent and the incongruent trials. These proportions were used to derive color-naming and wordreading process estimates by simultaneously solving the equations $p$ (correct/congruent $)=$ Word $+\operatorname{Color}(1-$ Word $)$ and $p$ (correct/incongruent $)=$ Color $(1-$ Word $)$. These data, which can be seen in the upper panel of Figure 1, show the same general pattern as that obtained by Lindsay and Jacoby and are virtually identical to those obtained by Spieler et al. (1996) for healthy younger and older adults. 
To compare the contributions of word reading and color naming at approximately equal points in processing for the two age groups, we recomputed the estimates, using the $z$ score deadlines recommended by Spieler et al. (1996). Specifically, deadlines were set at $-1.5,-1.0,-0.5,0.0$, $0.5,1.0$, and 1.5 standard deviations from a participant's mean color-naming latency, collapsed across trials. The younger and the older participants' color-naming and word-reading process estimates at these deadlines are shown in the lower panel of Figure 1. Because the data for these deadlines are not independent, separate one-way ANOVAs for age effects were done at the $-1.0,0.0$, and 1.0 deadlines for each type of estimate. There was no effect of age on color estimates at any of the three deadlines [all $F \mathrm{~s}(1,22)<1$ ], suggesting that the influence of color-naming processes on responding was similar for the younger and the older adults. There was also no effect of age on word-reading process estimates at the -1.0 deadline $\left[F(1,22)<1.00, M S_{\mathrm{e}}=0.009, \eta^{2}=.04\right]$, but the older adults' word estimates were higher than those of the younger adults at the 0.0 deadline $[F(1,22)=6.26$, $\left.M S_{\mathrm{e}}=0.021, \eta^{2}=.22\right]$ and the 1.0 deadline $[F(1,22)=$ $\left.7.24, M S_{\mathrm{e}}=0.017, \eta^{2}=.25\right]$. This suggests that wordreading processes were more influential in the responses of the older adults than in those of the younger adults and that, over the course of processing, the younger adults were more effective than the older adults at suppressing activated word information. These findings are very similar to those in Spieler et al. and provide evidence consistent with the argument that age differences in latencybased measures of interference are due to less effective suppression of word information. However, the higher
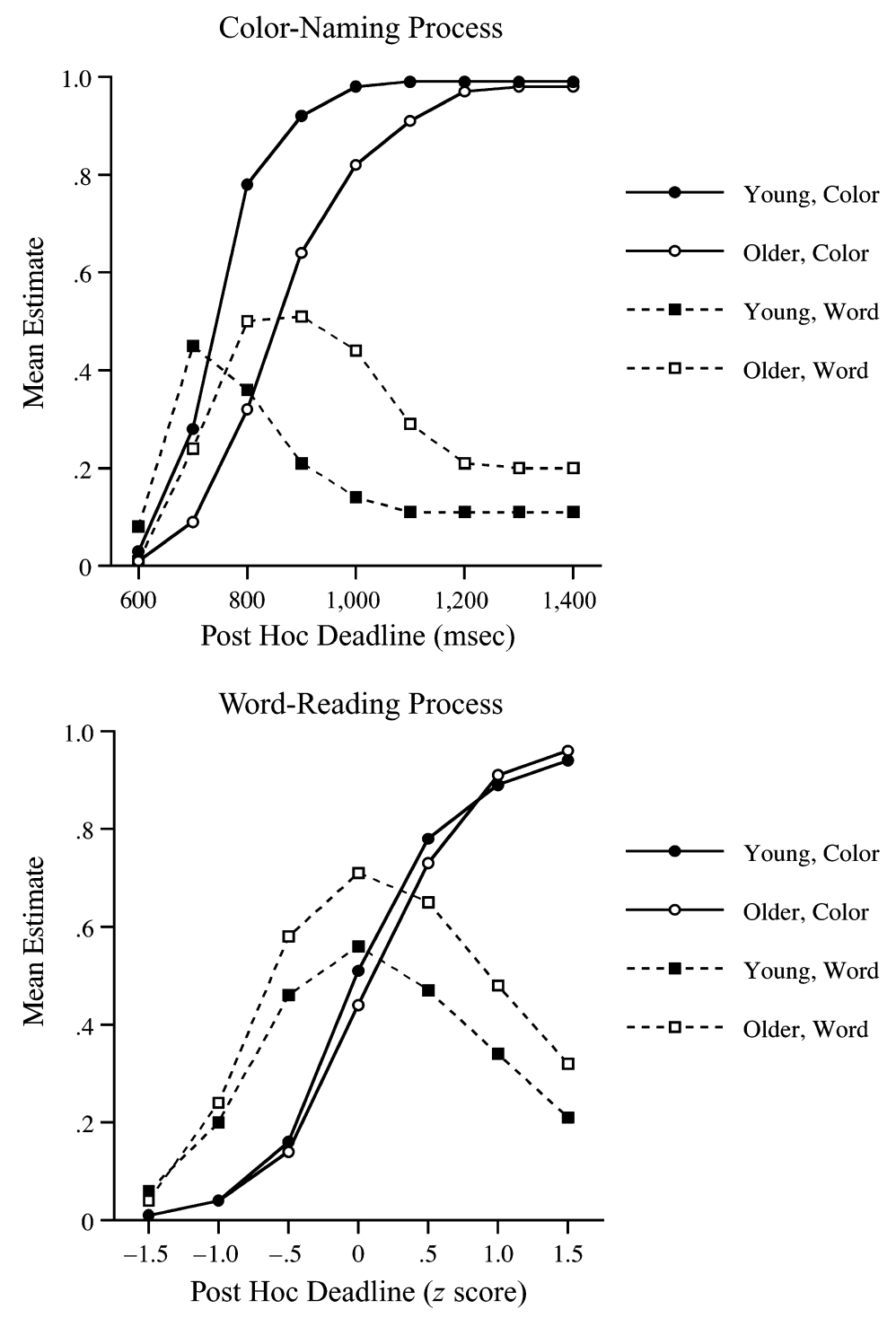

Figure 1. Color-naming and word-reading process estimates for young and older adults. Millisecond post hoc deadlines are shown in the upper panel, and $z$ score post hoc deadlines are shown in the lower panel. 
intrusion errors and facilitation in the older adults' responses also suggest that at least some of their difficulty in the standard Stroop task could be due to an inability to effectively represent and maintain the task context.

\section{EXPERIMENT 2}

In Experiment 2, age-related changes in the ability to represent varying Stroop task contexts were examined by manipulating the proportion of congruent and incongruent trials in the list. It was expected that younger participants who received a higher proportion of incongruent trials ( $80 \%$ incongruent and $20 \%$ congruent) would be more likely to exert greater control over color-naming and word-reading processes than would those who received a higher proportion of congruent trials $(80 \%$ congruent and $20 \%$ incongruent). This should be reflected in lower intrusion errors, lower facilitation, and lower interference for this group, as well as lower Stroop PD estimates for word reading and higher estimates for color naming. However, if older adults are less effective at representing different Stroop task contexts, they should show less variation in these measures across list composition, and age differences should be greatest for the more demanding mostly incongruent list.

\section{Method \\ Participants. Twenty-four younger adults $(M=22.95$ years, $S D=3.36)$ and 24 older adults $(M=69.42$ years, $S D=4.54)$ par- ticipated in this experiment. Demographic information for these participants and their scores on tests of basic cognitive ability can be found in Table 1 .}

Design and Materials. The design of this experiment was a 2 (age: younger vs. older) $\times 2$ (list composition: mostly congruent vs. mostly incongruent) $\times 3$ (trial type: congruent vs. neutral vs. incongruent) mixed factorial, with age and list composition as betweensubjects variables and trial type as a within-subjects variable. Twelve participants from each age group were randomly assigned to each list composition condition.

The stimuli were identical to those in the first experiment and were presented in the same way. Mostly congruent and mostly incongruent test lists were developed with these stimuli. Each list consisted of 140 trials. In the mostly congruent list, 100 trials were congruent, 20 trials were incongruent, and 20 trials were neutral; in the mostly incongruent list, 100 trials were incongruent, 20 trials were congruent, and 20 trials were neutral. For each trial type in these lists, the stimuli were presented equally often in each of the five print colors. In the mostly congruent list, the congruent trials consisted of the five color words presented 20 times each in their matching print color, and the incongruent trials consisted of the five color words presented once in each of the four nonmatching print colors. In the mostly incongruent list, the congruent trials consisted of the five color words presented 4 times each in their matching print color, and the incongruent trials consisted of the five color words presented 5 times in each of the four nonmatching print colors. In both of these lists, the neutral trials consisted of the string of percentage signs presented 4 times in each of the five print colors. Two 40 -trial practice lists with proportions of congruent, incongruent, and neutral trials similar to those for the mostly congruent or mostly incongruent lists were also constructed; however, not all word name and print color combinations were included in these lists. The congruent, incongruent, and neutral items were randomly assigned to list positions, using the same restrictions as those in Experiment 1.

Procedure. The procedure was identical to that in Experiment 1.

\section{Results and Discussion}

Intrusion errors and response latencies. The younger and the older participants' error rates for the congruent, incongruent, and neutral trials in each list composition condition are shown in Table 2. A 2 (age: younger vs. older) $\times 2$ (list composition: mostly congruent vs. mostly incongruent) ANOVA for arcsine-transformed error rates for the incongruent trials indicated that overall error rates were much higher for the mostly congruent list than for the mostly incongruent list $[F(1,44)=27.85$, $\left.\eta^{2}=.39\right]$. However, there was no main effect of age $\left[F(1,44)<1, M S_{\mathrm{e}}=0.14, \eta^{2}=.01\right]$, nor was there an age $\times$ list composition interaction $\left[F(1,44)<1, \eta^{2}=\right.$ $.04]$, showing that the older adults were no more likely than the younger adults to make word-reading errors in either list.

Mean response times for the congruent, incongruent, and neutral trials in the mostly congruent and mostly incongruent lists are shown in Table 2. Facilitation effects were analyzed with a 2 (age: younger vs. older) $\times 2$ (list composition: mostly congruent vs. mostly incongruent) $\times 2$ (trial type: congruent vs. neutral) mixed factorial ANOVA. There was a main effect of trial type $[F(1,44)=$ $\left.55.74, M S_{\mathrm{e}}=1,378.02, \eta^{2}=.56\right]$ but no interaction between age and trial type $\left[F(1,44)=1.13, M S_{\mathrm{e}}=1,378.02\right.$, $\left.\eta^{2}=.02\right]$, showing that the degree of facilitation did not differ in the younger $(M=49)$ and the older $(M=65)$ adults. There was an interaction between list composition and trial type $\left[F(1,44)=25.63, \eta^{2}=.37\right]$ but no threeway interaction between age, list composition, and trial type $\left[F(1,44)=1.59, \eta^{2}=.03\right]$, showing that for both the younger and the older adults, facilitation was greater for the mostly congruent $(M=95)$ than for the mostly incongruent $(M=18)$ list and that this was the case for both the younger and the older adults. The findings for facilitation thus resemble those for error rates. The high error rates for the participants who received the mostly congruent list suggest that these individuals frequently neglected the goal to ignore the word and identify the print color. In contrast, the participants who received the mostly incongruent list were much more likely to maintain this goal.

Interference effects in these data were analyzed with a 2 (age: younger vs. older) $\times 2$ (list composition: mostly congruent vs. mostly incongruent) $\times 2$ (trial type: incongruent vs. neutral) mixed factorial ANOVA. There was a main effect of trial type $\left[F(1,44)=188.45, M S_{\mathrm{e}}=\right.$ $\left.1,597.85, \eta^{2}=.81\right]$, revealing the presence of interference. However, this effect was qualified by an age $\times$ trial type interaction $\left[F(1,44)=7.29, \eta^{2}=.14\right]$, indicating that the older adults experienced more interference than the younger adults did (younger, $M=90$; older, $M=$ 134). There was also a list composition $\times$ trial type interaction $\left[F(1,44)=22,78, \eta^{2}=.34\right]$, showing that interference was greater in the mostly congruent list $(M=$ $151)$ than in the mostly incongruent list $(M=73)$. However, there was no interaction between age, list composition, and trial type $\left[F(1,44)<1, \eta^{2}=0\right]$, showing that the effect of list composition on interference was the same for the younger and the older adults. 
In sum, there were no age differences in intrusion errors or facilitation for either list in this experiment, and members of both age groups showed greater errors, more facilitation, and more interference for the mostly congruent list than for the mostly incongruent list. This suggests that there were no age differences in the task contexts established for these lists. However, the older adults consistently showed greater interference effects than the younger adults did. This outcome resembles Kane and Engle's (2003) findings for younger adults with low WM span and suggests that, despite the older adults' ability to represent and maintain the different task contexts, they were again less efficient at suppressing the irrelevant word information. If this is an accurate assessment, the same pattern of findings should also be reflected in the Stroop PD estimates. Specifically, although color-naming and word-reading process estimates for both younger and older adults should vary for lists with different proportions of congruent and incongruent trials, age differences should be present in word-reading estimates regardless of list composition.

Process dissociation estimates. The younger and the older participants' color-naming and word-reading PD estimates at $-1.5,-1.0,-0.5,0.0,0.5,1.0$, and $1.5 z$ score deadlines are shown in Figure 2. As in Experiment 1, separate 2 (age: younger vs. older) $\times 2$ (list composition: mostly congruent vs. mostly incongruent) ANOVAs were conducted for these estimates at the $-1.0,0.0$, and 1.0 deadlines. Analyses of color-naming process estimates indicated that there were main effects of list composition at each deadline $\left[-1.0\right.$ deadline, $F(1,44)=47.41, M S_{\mathrm{e}}=$ $0.002, \eta^{2}=.52 ; 0.0$ deadline, $F(1,44)=167.56, M S_{\mathrm{e}}=$ $0.02, \eta^{2}=.79 ; 1.0$ deadline, $F(1,44)=28.96, M S_{\mathrm{e}}=$ $\left.0.03, \eta^{2}=.40\right]$. However, there were no main effects of age and no interactions between age and list composition at any of the three deadlines [age, 1.0 deadline, $F(1,44)=1.040, M S_{\mathrm{e}}=0.001, \eta^{2}=.02 ; 0.0$ and 1.0 deadlines, $F(1,44)<1$; age $\times$ list composition, all deadlines, $F(1,44)<1]$. Thus, as in Experiment 1, there were no overall age differences in color-naming PD estimates. Moreover, for both the younger and the older adults, these estimates were consistently higher for the mostly incongruent list than for the mostly congruent list.

Analyses of word-reading process estimates revealed main effects of list composition at all three deadlines [list composition, -1.0 deadline, $F(1,44)=19.22, M S_{\mathrm{e}}=$ $0.02 ; \eta^{2}=.31 ; 0.0$ deadline, $F(1,44)=35.01, M S_{\mathrm{e}}=0.02$; $\eta^{2}=.44 ; 1.0$ deadline, $F(1,44)=222.18, M S_{\mathrm{e}}=0.02$, $\left.\eta^{2}=.83\right]$. Interestingly, these estimates were higher for the mostly incongruent than for the mostly congruent list at the -1.0 deadline, but this pattern was reversed at the later 0.0 and 1.0 deadlines. It is not clear why wordreading estimates would be higher for the mostly incongruent list early in processing, but one possibility is that the participants were devoting greater attentional resources to the activation of color information for this list, resulting in a temporary reduction in the resources available for suppression of word name information. It is also notable that the overall pattern seen in word-reading process estimates for the mostly congruent list was unlike the pattern in these estimates seen for the mostly incongruent list (or for the standard Stroop list used in Experiment 1). In the latter case, estimates showed an inverted U-shaped function over the post hoc deadlines. The form of this function reflects the diminishing effect of wordreading processes as attentional control processes suppress the influence of this information on responding (Trainham, Lindsay, \& Jacoby, 1997). In contrast, for the mostly congruent list, estimates continued to rise over the post hoc deadlines, suggesting that suppression of word-reading processes was greatly reduced.

There were main effects of age on word-reading process estimates at all but the first deadline $[-1.0$ deadline, $F(1,44)=3.58, M S_{\mathrm{e}}=0.02, p=.06, \eta^{2}=.07 ; 0.0$ deadline, $F(1,44)=6.25, M S_{\mathrm{e}}=0.02, \eta^{2}=.12 ; 1.0$ deadline, $\left.F(1,44)=6.61, M S_{\mathrm{e}}=0.02, \eta^{2}=.13\right]$, showing that word-reading estimates for the older adults were higher than those for the younger adults, especially later in processing. Finally, there were no age $\times$ list composition interactions in these estimates at the last two deadlines $\left[0.0, F(1,44)=1.92, \eta^{2}=.04 ; 1.0, F(1,44)=2.15\right.$, $\left.\eta^{2}=.05\right]$, indicating that age differences in word-reading process estimates were present for both list compositions at these deadlines. However, there was a trend to an age $X$ list composition interaction at the first deadline $[F(1,44)=$ $\left.2.73, p<.11, \eta^{2}=.06\right]$. Post hoc analyses of the effect of age for the mostly congruent list and the mostly incongruent list at this early deadline showed that, although not large, an effect of age was present for the mostly incongruent list $\left[F(1,22)=3.48, M S_{\mathrm{e}}=0.03\right.$, $\left.p<.07, \eta^{2}=.14\right]$, but not for the mostly congruent list $[F(1,22)<1]$. Thus, early in processing, age differences in the influence of word-reading processes on responding were somewhat greater for the mostly incongruent list than for the mostly congruent list.

These findings show that for both the younger and the older adults, color-naming processes were less influential and word-reading processes were more influential for the mostly congruent list than for the mostly incongruent list. This finding extends the results of the error and latency analyses and suggests that when the proportion of congruent trials was high, the participants in both age groups established a task context involving little modulation of the influence of color-naming and wordreading processes. In contrast, when the proportion of incongruent trials was high, they established a task context designed to boost the influence of color-naming processes and suppress the influence of word-reading processes. As in Experiment 1, the influence of colornaming processes in younger and older adults' responses was similar, suggesting that aging does not affect the efficiency of print color modulation. However, the outcome for word-reading processes was different. Although age differences in the influence of word-reading processes on responding were smaller early in processing when the proportion of congruent trials was high, these processes 


\section{Color-Naming Process}
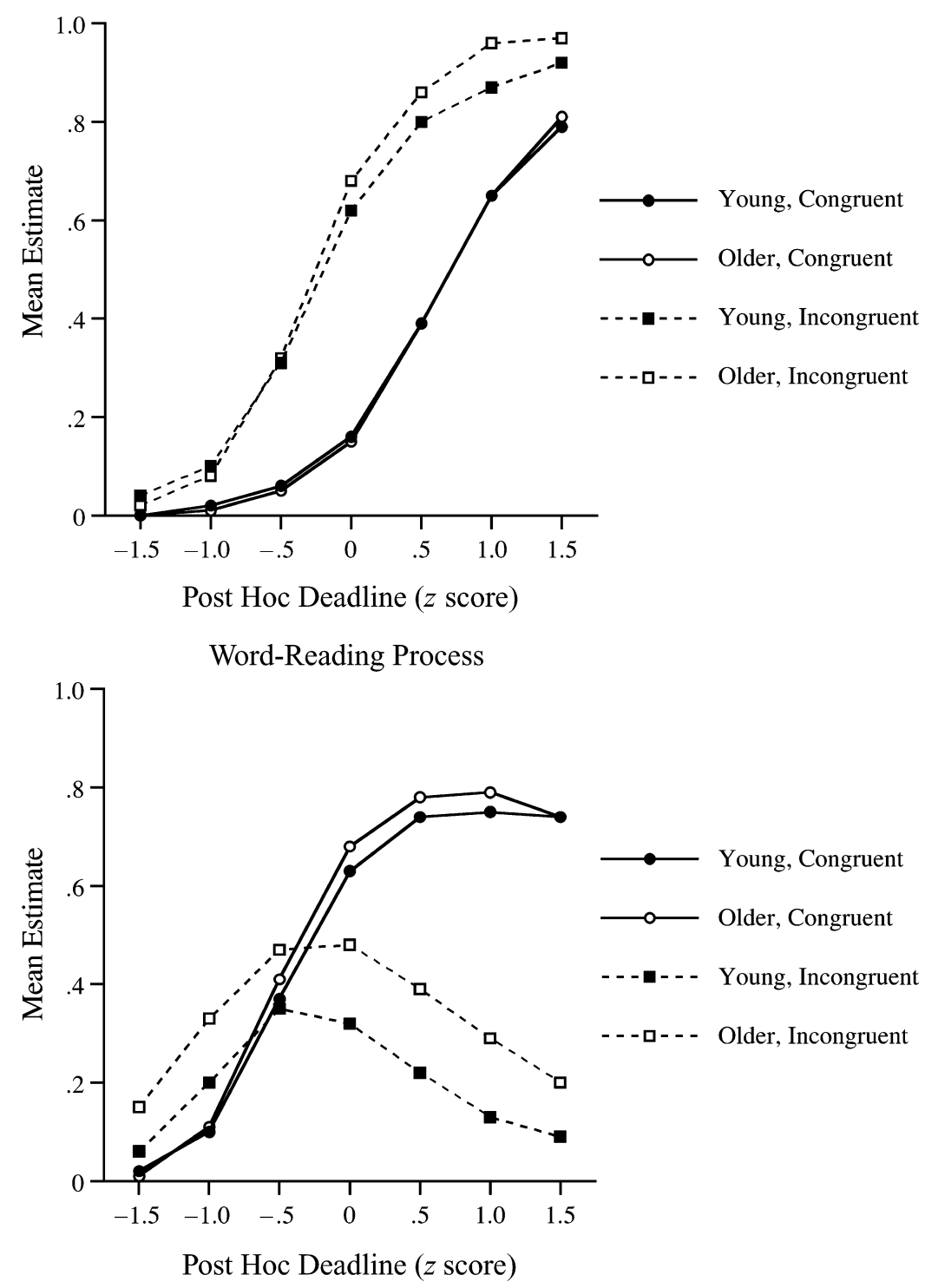

Figure 2. Color-naming and word-reading process estimates for young and older adults given mostly congruent and mostly incongruent lists ( $z$ score post hoc deadlines).

were generally more influential in the responses of the older adults than in those of the younger adults.

Together, these findings suggest that age-related changes in the ability to represent and maintain task context and in the ability to modulate color-naming processes did not contribute to the greater interference seen in the older adults' Stroop task performance in this experiment. Instead, this age difference was due to less efficient suppression of lexical information activated by habitual word-reading responses. This deficit is most clearly seen later in processing, when younger adults have had sufficient time to gain control over the activation of this information.

\section{EXPERIMENT 3}

In the previous two experiments, the print color and word name dimensions of the Stroop task stimuli were spatially contiguous, ensuring that both dimensions were simultaneously in focal attention. Under these conditions, it is especially difficult to select the relevant print color dimension and ignore the irrelevant word name dimension. Prior studies have shown, however, that spatially separating these dimensions in a display can aid attentional selection (e.g., Kahneman \& Henik, 1981) and that whether attention is narrowly or broadly focused depends on task context (Lowe \& Mitterer, 1982). When a 
list contains a high proportion of incongruent trials, younger adults narrow their attentional focus to the relevant color dimension. In contrast, when a list contains a high proportion of congruent trials, they maintain a broad attentional focus that includes both color and word dimensions, because the word dimension often provides relevant information for a response.

Spatial separation of the color and the word dimensions also provides benefits in older adults' Stroop performance. For example, Hartley (1993) has shown that age differences in Stroop interference are much smaller when color and word dimensions are separated than when they are integrated. We therefore separated the print color and the word name dimensions of the stimuli in the present experiment, using the Stroop priming task developed by Lowe and Mitterer (1982). In this task, a neutral target word appears in colored print with a prime word that is either an incongruent or congruent color word or a neutral noncolor word appearing to the left or the right of the target in black print. The participants are asked to name the print color of the target word and to ignore the prime word. In addition, we again manipulated the proportion of congruent and incongruent trials in the list. We expected that younger and older adults would again respond in similar ways to this manipulation of list composition and that separating the color and the word dimensions might enhance older adults' ability to ignore word information and, thereby, might eliminate age differences in interference and word-reading process estimates.

\section{Method}

Participants. Sixty younger adults $(M=19.67$ years, $S D=1.74)$ and 60 older adults $(M=71.98$ years, $S D=6.23)$ participated in this experiment. Demographic information for these participants and their scores on tests of basic cognitive ability can be found in Table 1.

Design and Materials. The design was a 2 (age: younger vs. older) $\times 5$ (list composition: $100 \mathrm{C} / 0 \mathrm{I}$ vs. $75 \mathrm{C} / 25 \mathrm{I}$ vs. $50 \mathrm{C} / 50 \mathrm{I}$ vs. $25 \mathrm{C} / 75 \mathrm{I}$ vs. $0 \mathrm{C} / 100 \mathrm{I}) \times 3$ (trial type: congruent vs. neutral vs. incongruent) mixed factorial with age and list composition as between-subjects variables and trial type as a within-subjects variable. List composition and trial type are not fully crossed in this design because the $100 \mathrm{C} / 0 \mathrm{I}$ and $0 \mathrm{C} / 100 \mathrm{I}$ lists do not contain all three trial types. As a result, the $100 \mathrm{C} / 0 \mathrm{I}$ list was not included in the analyses of interference effects, the $0 \mathrm{C} / 100 \mathrm{I}$ list was not included in the analyses of facilitation effects, and neither list was included in the PD analysis.

Response latencies were obtained using a voice-operated relay that was interfaced to the computer. The stimuli were similar to those used in Lowe and Mitterer (1982) and consisted of prime-target word pairs presented in a 24-point Helvetica font against a light gray background. The target in each word pair was always a neutral noncolor word that appeared in red, blue, or green print, and the prime was either a color word or a neutral word that always appeared in black print. The color words were red, blue, and green; the neutral words, which had the same number of letters as the color words, were far, most, and slant. There were thus nine different targets ( 3 neutral words $\times 3$ print colors) and six different primes ( 3 color words +3 neutral words).

The stimuli for each of the three trial types were constructed by varying the relation between the print color of the target and the meaning of the prime. For the congruent trials, the print color of the target matched the color named by the prime (e.g., the target slant in red print paired with the prime red in black print). For the incongruent trials, the print color of the target conflicted with the color named by the prime (e.g., the target most in red print paired with the prime word green in black print). For the neutral trials, the prime was always a noncolor word (the target far in red print paired with the prime word slant in black print). Eighteen unique congruent stimuli were created by combining nine targets, three matching color word primes, and two target positions relative to the fixation point (i.e., left or right); 36 unique incongruent stimuli were created by combining nine targets, each of the two conflicting color word primes, and two target positions; and 36 unique neutral stimuli were created by combining nine targets, each of the two nonmatching noncolor word primes, and two target positions.

These stimuli were used to generate five test lists with different proportions of congruent and incongruent trials. The congruent stimuli were divided into three sets of six prime-target pairs, and the incongruent and neutral stimuli were divided into six sets of six prime-target pairs. The prime-target pairs in these sets were arranged in three 60-trial blocks in the number required for a particular list composition, so that the pairs in each set were presented equally often across the three blocks. The number of congruent, incongruent, and neutral trials across the three blocks for each list composition is shown in Table 3. Within each block, the stimuli were arranged randomly, with the following constraints. To prevent negative priming, a color prime word on one trial was never followed by a target in the same print color on the next trial; to prevent positive priming, the same color word or target word print color on one trial was never presented on the same side of the fixation point on the following trial. The three blocks were repeated, for a total of 360 trials per list.

Procedure. Preliminary procedures (i.e., informed consent, color blindness test, demographic and health questionnaire) were identical to those in the first two experiments. After completion of these procedures, the participants were seated in front of the computer screen at a distance of $16 \mathrm{in}$. and wore headphones. They were told that they would receive a series of trials in which a fixation point $(+)$ would appear for a short period of time in the center of the computer screen and would be followed by a pair of words, one in black print and one in colored print. They were told to look directly at the fixation point until the word pair appeared and then to name the print color of the nonblack word as quickly as possible and before the occurrence of a warning signal. They were also told that the word with the colored print would sometimes appear to the right and sometimes to the left of the fixation point.

The participants completed a set of practice trials first and were given feedback on their performance and a reminder to respond before the warning signal. They then completed the test trials. For both the practice and the test trials, the fixation point appeared on the screen for $700 \mathrm{msec}$ and was followed, after a 50-msec blank screen, by a word pair that remained in sight for $120 \mathrm{msec}$. The participants had $650 \mathrm{msec}$ to make a vocal response before the warning tone occurred. After a response, the experimenter pressed one of three keys to code whether the response was correct, incorrect, or a false start (i.e., a cough, sneeze, etc.), or did not occur. A 2,000msec blank screen intervened between a response and the beginning of the next trial.

Table 3

Number of Congruent, Incongruent, and Neutral Stimuli Across Three Blocks of the Five Test Lists in Experiment 3

\begin{tabular}{cccc}
\hline List Composition & Congruent & Incongruent & Neutral \\
\hline $0 \mathrm{C} / 100 \mathrm{I}$ & 0 & 144 & 36 \\
$25 \mathrm{C} / 75 \mathrm{I}$ & 36 & 108 & 36 \\
$50 \mathrm{C} / 50 \mathrm{I}$ & 72 & 72 & 36 \\
$75 \mathrm{C} / 25 \mathrm{I}$ & 108 & 36 & 36 \\
$100 \mathrm{C} / 0 \mathrm{I}$ & 144 & 0 & 36 \\
\hline
\end{tabular}




\section{Results and Discussion}

Intrusion errors and response latencies. Error rates for the younger and the older participants for the congruent, incongruent, and neutral trials in each of the five list composition conditions are shown in Table 2. In this experiment, neutral trials could be included in the analysis of intrusion errors, because neutral words were used for these trials. However, because there were no incongruent trials for the $100 \mathrm{C} / 0 \mathrm{I}$ list composition, this list could not be included in these analyses. A 2 (age: younger vs. older) $\times 4$ (list composition: $75 \mathrm{C} / 25 \mathrm{I}$ vs. $50 \mathrm{C} / 50 \mathrm{I}$ vs. $25 \mathrm{C} / 75 \mathrm{I}$ vs. $0 \mathrm{C} / 100 \mathrm{I}) \times 2$ (trial type: incongruent vs. neutral) mixed factorial ANOVA for arcsine-transformed error rates revealed a main effect of age $[F(1,88)=3.86$, $\left.M S_{\mathrm{e}}=0.02, \eta^{2}=.04\right]$, showing that the older adults made more overall errors than the younger adults did. There was no main effect of list composition $[F(1,88)<1]$, nor was there an age $\times$ list composition interaction $[F(1,88)=$ $\left.1.08, \eta^{2}=.04\right]$, suggesting that error rates did not vary for the four list compositions and that differences between the younger and the older adults' error rates were consistent across all of the lists. There was a main effect of trial type $\left[F(1,88)=31.09, \eta^{2}=.26\right]$ but no interaction between this variable and list composition $[F(3,88)=1.60$, $\left.M S_{\mathrm{e}}=0.007, \eta^{2}=.05\right]$. Thus, for all four lists, the participants made more errors on the incongruent trials than on the neutral trials. Finally, there was an age $\times$ trial type interaction $\left[F(1,88)=4.37, \eta^{2}=.05\right]$ but no age $\times$ list composition $\times$ trial type interaction $[F(3,88)=2.17, p=$ $\left..10, \eta^{2}=.07\right]$. Separate analyses of errors for the incongruent trials and the neutral trials, collapsed over list composition, showed that the older adults made more errors than the younger adults did on incongruent trials $\left[F(1,94)=6.36, M S_{\mathrm{e}}=0.02, \eta^{2}=.06\right]$, but not on neutral trials $\left[F(1,94)<1, M S_{\mathrm{e}}=0.01, \eta^{2}=.0\right]$.

Mean response times for the congruent, incongruent, and neutral trials for the five list compositions are shown in Table 2. The influence of age and list composition on facilitation was examined by means of a 2 (age group: younger vs. older) $\times 4$ (list composition: $100 \mathrm{C} / 0 \mathrm{I}$ vs. $75 \mathrm{C} / 25 \mathrm{I}$ vs. $50 \mathrm{C} / 50 \mathrm{I}$ vs. $25 \mathrm{C} / 75 \mathrm{I}) \times 2$ (trial type: congruent vs. neutral) mixed factorial ANOVA. The 0C/ 100I list contained only incongruent and neutral trials and was not included in this analysis. There was a main effect of trial type $\left[F(1,88)=209.17, M S_{\mathrm{e}}=314.42, \eta^{2}=\right.$ $.70]$, as well as an age $\times$ trial type interaction $[F(1,88)=$ $\left.4.86, \eta^{2}=.05\right]$, showing that responses for congruent trials were faster than those for neutral trials and that this facilitation effect was greater for the older than for the younger adults. An interaction between list composition and trial type $\left[F(3,88)=10.45, \eta^{2}=.26\right]$ revealed that facilitation varied across the lists; however, this effect was qualified by an age $\times$ list composition $\times$ trial type interaction $\left[F(3,88)=3.04, \eta^{2}=.09\right]$. To further explore this interaction, we examined age differences in the facilitation effect separately for each of the four lists. There were no age differences for the $25 \mathrm{C} / 75 \mathrm{I}$ or the $50 \mathrm{C} / 50 \mathrm{I}$ lists [both $F_{\mathrm{s}}(1,22)<1$ ], but there was greater facilitation in the older adults' responses than in the younger adults' responses for the $75 \mathrm{C} / 25 \mathrm{I}[F(1,22)=$ $\left.6.17, M S_{\mathrm{e}}=681.02, \eta^{2}=.22\right]$ and the $100 \mathrm{C} / 0 \mathrm{I}[F(1,22)=$ $\left.8.15, M S_{\mathrm{e}}=524.95, \eta^{2}=.27\right]$ lists. This suggests that the older adults exerted less control over word reading in these lists than did the younger adults.

The influence of age and list composition on interference was examined by means of a 2 (age group: younger vs. older) $\times 4$ (list composition: $75 \mathrm{C} / 25 \mathrm{I}$ vs. $50 \mathrm{C} / 50 \mathrm{I}$ vs. $25 \mathrm{C} / 75 \mathrm{I}$ vs. $0 \mathrm{C} / 100 \mathrm{I}) \times 2$ (trial type: incongruent vs. neutral) mixed factorial ANOVA. The $100 \mathrm{C} / 0 \mathrm{I}$ list contained only congruent and neutral trials and is, therefore, not included in this analysis. There was a main effect of trial type $\left[F(1,88)=196.46, M S_{\mathrm{e}}=425.46, \eta^{2}=.69\right]$, as well as an interaction between age and trial type $\left[F(1,88)=21.17, \eta^{2}=.19\right]$, showing that despite the separation of the color and the word dimensions, interference was present in the participants' responses and was, once again, greater for the older than for the younger adults. There was also an interaction between list composition and trial type $\left[F(3,88)=3.15, \eta^{2}=.10\right]$, but the three-way interaction between age, list composition, and trial type was not significant $\left[F(3,88)<1, \eta^{2}=.02\right]$. Contrast analyses of interference effects (incongruent response time - neutral response time) for the three lists, collapsed across age group, revealed that interference was greatest for the two lists with the highest proportions of congruent trials $(75 \mathrm{C} / 25 \mathrm{I}=50 \mathrm{C} / 50 \mathrm{I}>25 \mathrm{C} / 75 \mathrm{I}=$ $0 \mathrm{C} / 100 \mathrm{I})$. Thus, the amount of interference decreased with increasing numbers of incongruent trials for both the younger and the older adults. However, in contrast to our prediction, spatially separating the print color and the word name dimensions did not eliminate age differences in interference.

Overall means for intrusion errors and facilitation and interference effects were substantially smaller in this experiment than in the two previous experiments, suggesting that spatially separating the print color and the word name dimensions did improve our participants' ability to select the relevant color dimension for a response. Further support for this idea comes from the finding that increasing the proportion of congruent trials in the list did not produce greater errors for the incongruent trials, as it did in Experiment 2. The participants in both age groups were better able to withhold conflicting word responses in this experiment, even when the list composition encouraged them to direct attention to the prime (i.e., $75 \mathrm{C} / 25 \mathrm{I}$ list). However, even with spatial separation, the presence of a conflicting color word name in the display produced interference and facilitation effects. As in Experiment 2, these effects were lowest for the younger and the older adults in lists composed of mostly incongruent trials than in lists composed of mostly congruent trials, suggesting that both groups again established different task contexts for these lists. When they expected a high proportion of incongruent trials, they more selectively focused on the target, but when they expected a high proportion of congruent trials, they included the prime in their attentional focus. 
Despite the similarity in the younger and the older adults' overall responses to list composition, the older adults were generally more likely to give the prime word as a response than were the younger adults. Thus, as in Experiment 1, the older adults in this experiment suffered occasional failures to maintain task context. The presence of age differences in facilitation for lists with higher proportions of congruent trials (i.e., $100 \mathrm{C} / 0 \mathrm{I}$, $75 \mathrm{C} / 25 \mathrm{I}$ ) suggests that they made little attempt to control these responses in these lists, whereas the absence of age differences in facilitation for lists with higher proportions of incongruent trials (i.e., 25C/75I, 50C/50I) suggests that they did attempt, although sometimes unsuccessfully, to control word reading in these lists. Finally, in contrast to our prediction, interference was again higher in the older adults' responses than in the younger adults' responses, regardless of list composition. Although the color and the word dimensions of the Stroop stimulus were spatially separated, the older adults were still less efficient at suppressing the activation of word information than were the younger adults.

Process dissociation estimates. Younger and older participants' color-naming and word-reading estimates at the seven $z$ score deadlines are shown in Figure 3. The effect of age and list composition on these estimates at the $-1.0,0.0$, and 1.0 deadlines was examined with separate 2 (age group: younger vs. older) $\times 3$ (list composition: $75 \mathrm{C} / 25 \mathrm{I}$ vs. $50 \mathrm{C} / 50 \mathrm{I}$ vs. $25 \mathrm{C} / 75 \mathrm{I})$ ANOVAs. Analyses of color-naming estimates revealed main effects of list composition at all three deadlines [ -1.0 deadline, $F(2,66)=6.31, M S_{\mathrm{e}}=0.002, \eta^{2}=.16 ; 0.0$ deadline, $F(2,66)=30.24, M S_{\mathrm{e}}=0.004, \eta^{2}=.48 ; 1.0$ deadline, $\left.F(2,66)=3.78, M S_{\mathrm{e}}=0.001, \eta^{2}=.10\right]$, and contrast analyses of these effects showed that at each deadline, color-naming estimates were highest for the list with the greatest number of incongruent trials $(75 \mathrm{C} / 25 \mathrm{I} \leq$ $50 \mathrm{C} / 50 \mathrm{I}<25 \mathrm{C} / 75 \mathrm{I})$. There were again no main effects of age in these estimates at any of the deadlines $[-1.0$ deadline, $F(1,66)=2.01, \eta^{2}=.03 ; 0.0$ deadline, $F(1,66)=$ $1.28, \eta^{2}=.02 ; 1.0$ deadline, $F(1,66)<1, \eta^{2}=.00$ ], nor were there any interactions between age and list compositions [ -1.0 deadline, $F(2,66)<1, \eta^{2}=0 ; 0.0$ deadline, $F(2,66)=1.42, \eta^{2}=.04 ; 1.0$ deadline, $F(2,66)=2.28$, $\left.\eta^{2}=.06\right]$. Thus, as in Experiment 2, the influence of color-naming processes on responding was greatest for the list with the highest proportion of incongruent trials. The fact that this effect again did not differ for the younger and the older adults provides further evidence that modulation of color naming does not decline with age.

Analyses of word-reading PD estimates revealed main effects of list composition at the -1.0 deadline $[F(2,66)=$ 3.33, $\left.M S_{\mathrm{e}}=0.005, \eta^{2}=.09\right]$ and the 1.0 deadline $\left[F(2,66)=8.79, M S_{\mathrm{e}}=0.008, \eta^{2}=.21\right]$, but not at the 0.0 deadline $\left[F(2,66)=1.75, M S_{\mathrm{e}}=0.002, \eta^{2}=.05\right]$. Contrast analyses for the effect at the -1.0 deadline indicated that estimates were higher for the lists containing greater numbers of incongruent trials $(75 \mathrm{C} / 25 \mathrm{I}<50 \mathrm{C} / 50 \mathrm{I}=$ $25 \mathrm{C} / 75 \mathrm{I})$. This outcome was also observed for word pro- cess estimates at this early deadline in Experiment 2 and may reflect the greater resource demands for print color naming in these lists. Contrast analyses for the 1.0 deadline revealed higher word-reading estimates for the $75 \mathrm{C} / 25 \mathrm{I}$ list than for the other lists $(75 \mathrm{C} / 25 \mathrm{I}>$ $50 \mathrm{C} / 50 \mathrm{I}=25 \mathrm{C} / 75 \mathrm{I}$ ), suggesting that the word-reading process remained influential in responding for a longer time when there was a high proportion of congruent trials in the list than when there was a high proportion of incongruent trials. There were main effects of age in word-reading estimates at the -1.0 deadline $[F(2,66)=$ $\left.12.04, \eta^{2}=.15\right]$, the 0.0 deadline $\left[F(2,66)=7.75, \eta^{2}=\right.$ $.10]$, and the 1.0 deadline $\left[F(2,66)=3.63, p<.06, \eta^{2}=\right.$ $.05]$. The absence of any age $\times$ list composition interactions at these deadlines $[-1.0$ deadline, $F(2,66)=2.27$, $\eta^{2}=.06 ; 0.0$ and 1.0 deadlines, both $\left.F \mathrm{~s}(2,66)<1\right]$ shows that the older adults' word-reading process estimates were consistently greater than those of the younger adults for all three list compositions.

These findings resemble the results of Experiment 2 in showing that, for both the younger and the older adults, color-naming processes were more influential when the proportion of incongruent trials was high, whereas wordnaming processes were more influential when the proportion of congruent trials was high. This provides additional evidence that members of the two age groups represented the task context in similar ways. When they expected a high proportion of incongruent trials, they were more likely to focus on the target, which always conveyed accurate print color information; when they expected a high proportion of congruent trials, they were more likely to distribute their attention to both the target and the prime, which frequently provided congruent color word information. This outcome supports and extends the findings reported in Lowe and Mitterer (1982). The absence of age differences in color-naming process estimates provides converging evidence that older adults have little difficulty modulating this process. However, older adults' responses were again more strongly influenced by the word-reading process than were younger adults' responses. We had predicted that separating the color and the word dimensions of the Stroop stimulus would eliminate age differences in the influence of this process. That this did not occur suggests that older adults are less efficient at suppressing activated word information even when the environment provides some support for this process.

\section{GENERAL DISCUSSION}

This study of age differences in the ability to represent and use Stroop task context has produced two major findings. First, consistent with current models of the Stroop effect (Cohen et al., 1990), varying the proportion of congruent and incongruent trials induced the participants to establish different task contexts, which, in turn, led to different patterns in their performance. More important, this effect did not vary with age. In Experi- 
ment 2, error and latency analyses suggested that the participants in both age groups were more likely to suppress the activation of word information when the list contained a high proportion of incongruent trials than when it contained a high proportion of congruent trials. In support of this idea, the younger and the older adults' process dissociation estimates for word reading were lower for the mostly incongruent list than for the mostly congruent list. This difference for word-reading estimates resembles earlier findings by Lindsay and Jacoby (1994, Experiment 3). However, we also found that estimates for color naming were higher for the mostly incongruent list than for the mostly congruent list, which was not observed in their earlier experiment. It is not clear what could account for the different outcomes for color-naming estimates in the two studies. Our findings suggest, however, that the younger and the older participants modulated the influence of both word-reading and color-naming processes in response to task context.

We obtained a similar pattern of findings in Experiment 3. Although the color and the word dimensions of the Stroop stimuli were separated in this experiment, facilitation and interference effects were again observed for the younger and the older adults, and for members of
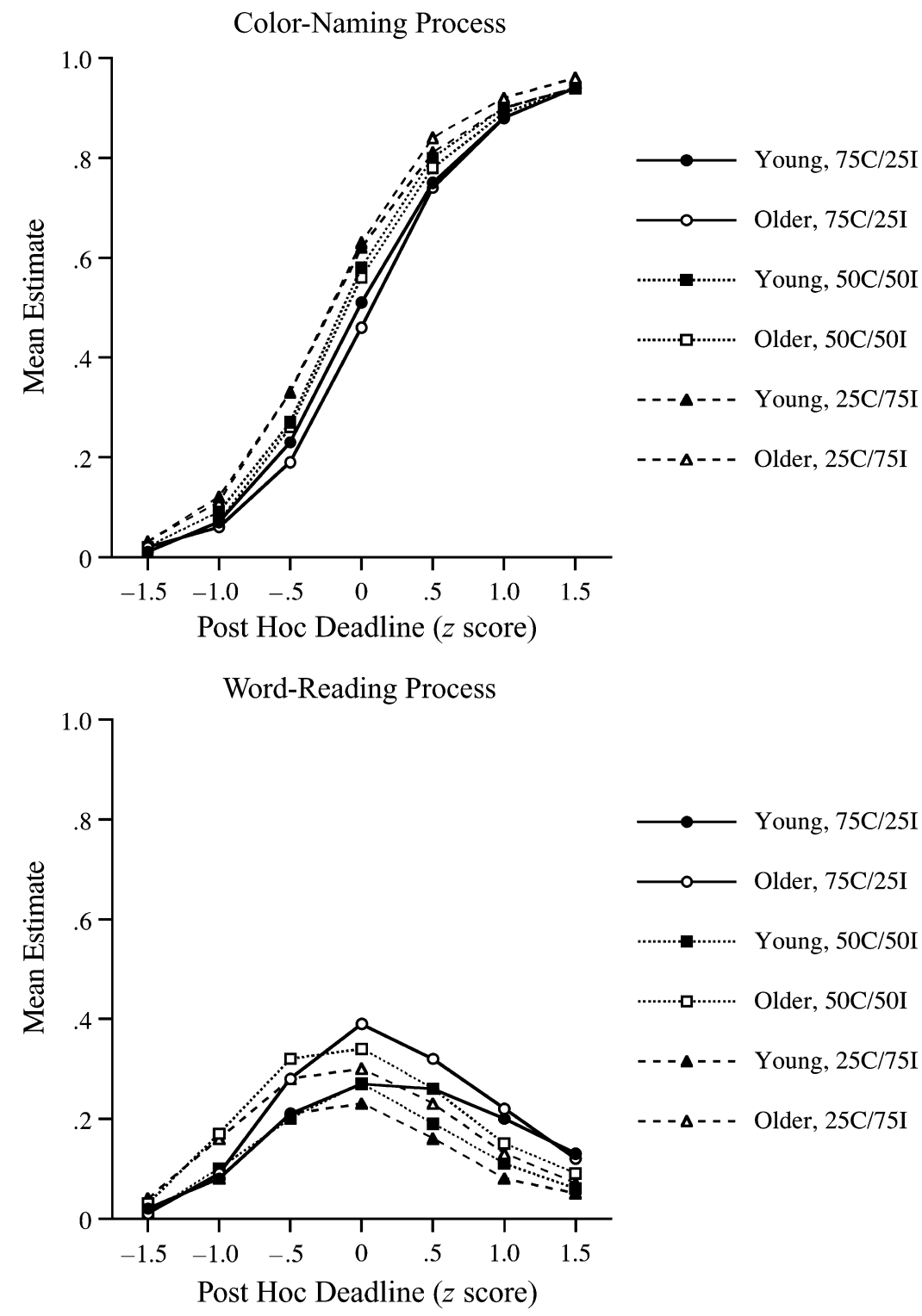

Figure 3. Color-naming and word-reading process estimates for young and older adults given $75 \mathrm{C} / 25 \mathrm{I}, 50 \mathrm{C} / 50 \mathrm{I}$, and $25 \mathrm{C} / 75 \mathrm{I}$ lists ( $z$ score post hoc deadlines). 
both age groups, these effects were higher for lists containing greater proportions of congruent trials than for lists containing greater proportions of incongruent trials. These findings are consistent with those reported in Lowe and Mitterer (1982) and suggest that when the participants expected a high proportion of congruent trials, they distributed their attentional resources to both the target item conveying print color information and the prime item conveying word information, but when they expected a high proportion of incongruent trials, they more selectively attended to the target item. The analysis of PD estimates supported this conclusion. As in Experiment 2 , the influence of word reading on responding was highest for the list containing the most congruent trials, whereas the influence of color naming was highest for the lists containing high proportions of incongruent trials.

These findings show that younger and older adults respond in similar ways to variations in list composition and, thus, provide little support for the idea that age differences in Stroop interference are due to a failure to adequately represent task context. On the other hand, the pattern of findings for intrusion errors and facilitation across the three experiments suggests that the older adults had more difficulty maintaining the context in some conditions than in others. Specifically, the absence of age differences in intrusions and facilitation in Experiment 2 suggests that the older adults maintained effective representations of the task context in this experiment, whereas the presence of age differences in these measures in Experiments 1 and 3 suggests that, in these experiments, they did not. These different outcomes may be related to the degree of stimulus uncertainty or ambiguity in the three experiments. The lists used in Experiment 2 provided highly reliable information about the type of stimulus that was likely to occur. In contrast, in Experiment 1, there was uncertainty as to whether a congruent or an incongruent stimulus would appear, and in Experiment 3, there was uncertainty as to where the target stimulus would appear in the display. According to Mayr (2001), stimulus ambiguity may induce participants to engage in a costly process of updating task context as stimulus presentation occurs. It may thus be the case that older adults are able to maintain a representation of the Stroop task context when there is little need for changing this representation but that they are likely to suffer transient failures in this process when a high degree of stimulus uncertainty requires constant updating of this representation (Mayr, 2001).

The second major finding was that the older adults showed no deficit in their ability to modulate the activation of print color information in response to task context but that they were consistently less efficient at suppressing word information. Before turning to the evidence for this conclusion, it is important to note that our findings are also consistent with the idea that color naming is a slower, more controlled process than word reading is (Posner \& Snyder, 1975) and that age differences are greater in the time to identify colors than in the time to read words (e.g., West \& Baylis, 1998). In our study (see Figure 1) and in prior research using Stroop PD analysis (i.e., Lindsay \& Jacoby, 1994; Spieler et al., 1996), word reading dominated responding early in processing, whereas color naming dominated later in processing. Moreover, the younger adults' peak color-naming estimates occurred from 200 to $300 \mathrm{msec}$ earlier than did the older adults' peak estimates, whereas their peak word reading estimates occurred only 100-200 msec earlier. The same pattern can be seen in data from Spieler et al. Thus, age is associated with a longer delay in initiating controlled color-naming processes than in initiating habitual word-reading processes.

If the same attentional mechanism is responsible for modulating both color-naming and word-reading processes, this may explain the somewhat counterintuitive finding that word process estimates were higher for mostly incongruent than for mostly congruent lists at early deadlines when boosting activation of color information might take resources away from suppressing activation of word information. Likewise, the lag in the older adults' color name processing may be due to competition for resources between this process and the suppression of activation of word information (West \& Alain, 2000a). Our results do not rule out this possibility, but they do suggest that the ability to modulate the influence of color naming is more resistant to the effects of age than is the ability to modulate the influence of word reading. After adjusting the younger and the older adults' PD estimates to reflect equivalent points in processing, we replicated Spieler et al.'s (1996) finding that the contribution of the colornaming process to younger and older adults' performance in the standard Stroop task did not vary, and we extended this finding to lists with different proportions of congruent and incongruent trials. Thus, despite the lag in the older adults' color name processing, there were no age differences in the eventual contribution that this process made to Stroop responding. However, the same cannot be said for the word-reading process. Over the course of processing, word-reading processes were more influential in the older adults' responses than in the younger adults' responses in a standard Stroop list and in lists composed of high proportions of incongruent or congruent trials, even when the conflicting color and word dimensions in these lists were spatially separated. These findings are thus consistent with the idea that responding in the Stroop task involves modulation of both color information and word information (cf. Cohen et al., 1990; Dulaney \& Rogers, 1994) and that age affects primarily the latter.

Older adults are able to produce and maintain different representations of task context in response to different task demands, but they seem to have difficulty when required to constantly update these representations, due to stimulus uncertainty. Moreover, older adults are able to boost the activation of print color information, but they are consistently inefficient at suppressing the activation 
of word information. This pattern of findings resembles Kane and Engle's (2003) findings for young adults with low WM spans and is clearly compatible with recent models of the Stroop effect (e.g., Cohen et al., 1990) and with theories of age-related inhibitory decline (Hasher \& Zacks, 1988). It is also consistent with recent neurocognitive models of attention that suggest that there are distinct attentional systems in anterior and posterior regions of the brain (Posner, 1992). The posterior attentional system, supported by structures in the parietal cortex, the pulvinar nucleus of the thalamus, and the superior colliculus, selects visual stimuli on the basis of physical attributes, such as color, shape, location, and movement, and is relatively resistant to the effects of aging (e.g., Hartley, 1993; West \& Alain, 2000a; West \& Bell, 1997). The anterior attentional system, supported by structures in the prefrontal cortex and the anterior cingulate gyrus, is responsible for representing and maintaining task context and for modulating activity in posterior processing regions by boosting or amplifying activation of relevant information and suppressing activation of irrelevant information (e.g., Braver et al., 2001; West \& Alain, 2000b).

Several studies have documented age-related changes in the structure and functioning of the frontal lobes (for an overview of this literature, see Raz, 2000), and there is considerable evidence that these changes contribute to a reduction in the efficiency of the anterior attentional system. For example, older adults' difficulties inhibiting word information in the Stroop task are similar to those shown by patients with frontal lobe dysfunction (Hartley, 1993). Older adults show decreased activity in the dorsolateral prefrontal cortex (dPFC), relative to younger adults, during both congruent and incongruent trials in the standard Stroop task, as well as a negative correlation between activity within the $\mathrm{PPFC}$ and activity in various structures associated with lexical processing, suggesting that compromised functioning of the $\mathrm{APFC}$ is associated with greater activation of irrelevant word information for older adults (Milham et al., 2001). In further support of this idea, West and Alain (2000a) have observed an agerelated attenuation in midline frontocentral and left parietalfrontal bilateral event-related potential modulations, which are thought to reflect the inhibition or suppression of conflicting word information in incongruent trials, but no age differences in left temporo-parietal modulations, which are thought to reflect the facilitation of processing for task-relevant print color information. Thus, the behavioral manifestations of older adults' difficulty in updating task context and their less efficient suppression of word information are very likely associated with agerelated changes in the anterior attentional system.

One other finding from this study is worth mentioning. In contrast to our predictions and to Hartley's (1993) work showing that spatial separation of word and color dimensions eliminated age differences in interference, we found that this manipulation did not eliminate age differences either in interference or in word-reading PD estimates. We suspect that this is due to procedural dif- ferences between the two studies. Hartley's participants could avoid reading the conflicting color word altogether, because the target providing the color information was preceded by a cue showing where it would appear relative to a fixation point. According to Hartley, this allowed spatial selection of the target location via the posterior attentional system prior to the appearance of the conflicting color word (see also West \& Bell, 1997). In the present experiment, no cues were provided, and targets and primes appeared randomly to the left or right of fixation. As was mentioned previously, this introduced an element of uncertainty into the task. Under these circumstances, to locate the target in the display, younger and older adults had to maintain a broad attentional focus until the target and the prime appeared. Habitual wordreading processes would be engaged for the prime before attentional narrowing could occur, thereby activating conflicting word information and requiring the involvement of the anterior attentional system to suppress this activation. Thus, age-related decline in this attentional system would again explain the greater influence of word information seen in our older adults' responses in the Stroop priming task. An interesting question for future research is whether reducing the involvement of the anterior attentional system by precuing the location of the target stimulus might eliminate age differences in interference and word-reading PD estimates in the Stroop priming task, as well as in other versions of this task.

In conclusion, this study has shown that older adults are able to evaluate Stroop task demands and to modify their global representations of task context in response to this knowledge, but they may be less able than younger adults to update these representations on a trial-by-trial basis under conditions of stimulus uncertainty. Moreover, although there does not appear to be any decline in older adults' ability to boost the activation of print color information, they are consistently less able to suppress the activation of conflicting word information. These findings suggest that although age differences in the Stroop task may be magnified under conditions, such as stimulus uncertainty, that promote transient failures to maintain task context, the primary source of these differences is a more enduring decline in the efficiency of processes that are responsible for suppressing the activation of irrelevant lexical information.

\section{REFERENCES}

Baddeley, A., \& Hitch, G. J. (1974). Working memory. In G. H. Bower (Ed.), The psychology of learning and motivation: Advances in research and theory (Vol. 8, pp. 47-89). New York: Academic Press.

Benton, A. L., \& HAMsher, K. DE S. (1989). Multilingual aphasia examination. Iowa City: AJA Associates.

Besner, D., \& Stolz, J. A. (1999). Unconsciously controlled processing: The Stroop effect reconsidered. Psychonomic Bulletin \& Review, 6, 449-455.

Besner, D., Stolz, J. A., \& Boutilier, C. (1997). The Stroop effect and the myth of automaticity. Psychonomic Bulletin \& Review, 4, 221-225.

Braver, T. S., Barch, D. M., Keys, B. A., Carter, C. S., Cohen, J. D., 
Kaye, J. A., Janowsky, J. S., Taylor, S. F., Yesavage, J. A., Mumenthaler, M. S., Jagust, W. J., \& Reed, B. R. (2001). Context processing in older adults: Evidence for a theory relating cognitive control to neurobiology in healthy aging. Journal of Experimental Psychology: General, 130, 746-763.

Cheesman, J., \& Merikle, P. M. (1986). Distinguishing conscious from unconscious perceptual process. Canadian Journal of Psychology, 40, 343-367.

Cohen, J. D., Dunbar, K., \& McClelland, J. L. (1990). On the control of automatic processes: A parallel distributed processing model of the Stroop effect. Psychological Review, 97, 332-361.

Cohn, N. B., Dustman, R. E., \& Bradford, D. C. (1984). Age-related decrements in Stroop color test performance. Journal of Clinical Psychology, 40, 1244-1250.

COMALli, P. E., WAPNER, S., \& Werner, H. (1962). Interference effects of Stroop color-word test on childhood, adulthood, and aging. Journal of Genetic Psychology, 100, 47-53.

Corbetta, M., Miezin, F. M., Dobmeyer, S., Shulman, G. L., \& PeTERSEN, S. E. (1990). Attentional modulation of neural processing of shape, color, and velocity in humans. Science, 248, 1556-1559.

Dulaney, C. L., \& Rogers, W. A. (1994). Mechanism underlying reduction in Stroop interference with practice for young and old adults. Journal of Experimental Psychology: Learning, Memory, \& Cognition, 20, 470-484.

HaRTLEy, A. A. (1993). Evidence for the preservation of spatial selective attention in old age. Psychology \& Aging, 8, 371-379.

HASHER, L., \& ZACKS, R. T. (1988). Working memory, comprehension, and aging: A review and a new view. In G. H. Bower (Ed.), The psychology of learning and motivation (Vol. 22, pp. 193-225). San Diego: Academic Press.

Hillstrom, A. P., \& Logan, G. D. (1997). Process dissociation, cognitive architecture, and response time: Comments on Lindsay and Jacoby (1994). Journal of Experimental Psychology: Human Perception \& Performance, 23, 1561-1578.

Houx, P. J., Jolles, J., \& Vreeling, F. W. (1993). Stroop interference: Aging effects assessed with the Stroop color-word test. Experimental Aging Research, 19, 209-224.

IsHIHARA, S. (1994). Ishihara's tests for colour-blindness: Concise edition. Tokyo: Kanehara.

Jacoby, L. L., McElree, B., \& Trainham, T. N. (1999). Automatic influences as accessibility bias in memory and Stroop tasks: Toward a formal model. In D. Gopher \& A. Koriat (Eds.), Attention and performance XVII: Cognitive regulation of performance. Interaction of theory and application (pp. 461-486). Cambridge, MA: MIT Press.

Kahneman, D., \& HeniK, A. (1981). Perceptual organization and attention. In M. Kubovy \& J. R. Pomerantz (Eds.), Perceptual organization (pp. 181-211). Hillsdale, NJ: Erlbaum.

KANE, M. J., \& ENGLE, R. W. (2003). Working-memory capacity and the control of attention: The contributions of goal neglect, response competition, and task set to Stroop interference. Journal of Experimental Psychology: General, 132, 47-70.

LINDSAY, D. S., \& JACOBY, L. L. (1994). Stroop process dissociations: The relationship between facilitation and interference. Journal of Experimental Psychology: Human Perception \& Performance, 20, 219-234.

LogAN, G. D., \& ZBRodofF, N. J. (1979). When it helps to be misled: Facilitative effects of increasing the frequency of conflicting stimuli in a Stroop-like task. Memory \& Cognition, 7, 166-174.

Logan, G. D., Zbrodoff, N. J., \& Williamson, J. (1984). Strategies in the color-word Stroop task. Bulletin of the Psychonomic Society, 22, $135-138$

Long, D. L., \& PRAT, C. S. (2002). Working memory and Stroop interference: An individual differences investigation. Memory \& Cognition, 30, 294-301.

Lowe, D. G., \& MitTerer, J. O. (1982). Selective and divided attention in a Stroop task. Canadian Journal of Psychology, 36, 684-700.

MacLEOD, C. M. (1991). Half a century of research on the Stroop effect: An integrative review. Psychological Bulletin, 109, 163-203.

MacLeod, C. M., \& MacDonald, P. A. (2000). Interdimensional interference in the Stroop effect: Uncovering the cognitive and neural anatomy of attention. Trends in Cognitive Sciences, 4, 383-391.
MaYr, U. (2001). Age differences in the selection of mental sets: The role of inhibition, stimulus ambiguity, and response-set overlap. Psychology \& Aging, 16, 96-109.

Milham, M. P., Erickson, K. I., Banich, M. T., Kramer, A. F., Webb, A., WszaleK, T., \& COHEN, N. J. (2001). Attentional control in the aging brain: Insights from an fMRI study of the Stroop task. Brain \& Cognition, 49, 277-296.

Posner, M. I. (1992). Attention as a cognitive and neural system. Current Directions in Psychological Science, 1, 11-14.

Posner, M. I., \& SNYder, C. R. R. (1975). Attention and cognitive control. In R. L. Solso (Ed.), Information processing and cognition: The Loyola symposium (pp. 55-85). Hillsdale, NJ: Erlbaum.

RAZ, N. (2000). Aging of the brain and its impact on cognitive performance: Integration of structural and functional findings. In F. I. M. Craik \& T. A. Salthouse (Eds.), The handbook of aging and cognition (2nd ed., pp. 1-90). Mahwah, NJ: Erlbaum.

Salthouse, T., \& Babcock, R. L. (1991). Decomposing adult age differences in working memory. Developmental Psychology, 27, 763 776

Shallice T., \& Burgess, P. (1993). Supervisory control of action and thought selection. In A. Baddeley \& L. Weiskrantz (Eds.), Attention: Selection awareness and control. A tribute to Donald Broadbent (pp. 171-187). Oxford: Oxford University Press, Clarendon Press. Spieler, D. H., Balota, D. A., \& Faust, M. E. (1996). Stroop performance in healthy younger and older adults and in individuals with dementia of the Alzheimer's type. Journal of Experimental Psychology: Human Perception \& Performance, 22, 461-479.

Stroop, J. R. (1935). Studies of interference in serial verbal reactions. Journal of Experimental Psychology, 18, 643-661.

Trainham, T. N., Lindsay, D. S., \& JaCoby, L. L. (1997). Stroop process dissociations: Reply to Hillstrom and Logan (1997). Journal of Experimental Psychology: Human Perception \& Performance, 23, 1579-1587.

WECHSLER, D. (1981). Wechsler adult intelligence scale-revised. San Antonio, TX: Psychological Corporation.

WeSt, R., \& Alain, C. (2000a). Age-related decline in inhibitory control contributes to the increased Stroop effect observed in older adults. Psychophysiology, 37, 179-189.

West, R., \& Alain, C. (2000b). Effects of task context and fluctuations of attention on neural activity supporting performance of the Stroop task. Brain Research, 873, 102-111.

WEST, R., \& BAYLIS, G. C. (1998). Effects of increased response dominance and contextual disintegration on the Stroop interference effect in older adults. Psychology \& Aging, 13, 206-217.

WEST, R., \& BELL, M. A. (1997). Stroop color-word interference and electroencephalogram activation: Evidence for age-related decline of the anterior attentional system. Neuropsychology, 11, 421-427.

\section{NOTES}

1. The Stroop PD procedure is not without critics. Hillstrom and Logan (1997) have argued that because Stroop PD is not backed by a theoretical model that can account for both response time and response accuracy, there is considerable ambiguity in the key terms and concepts of the procedure. In response, Jacoby and his colleagues (Jacoby, McElree, \& Trainham, 1999; Trainham, Lindsay, \& Jacoby, 1997) have clarified the Stroop PD concepts and assumptions. Their Stroop counter model assumes that a response is determined by the number of counts provided to a set of response counters that correspond to the possible color names. Counts occur at discrete intervals in a trial and gradually accrue over time until one response counter acquires a criterion number of counts more than the other response counters have. The allocation of an interval's count to a particular response counter is determined by the relative influence of word-reading and color-naming processes in that interval. Similar to the parallel distributed processing model that serves as the framework for the present research (i.e., Cohen et al., 1990), the role of attention in the counter model is to select one of these processes in response to task demands. According to Trainham et al. (1997), the relative influence of word-reading and color-naming processes on responding at a particular interval can be estimated with the same equations used to es- 
timate their influence on overall performance. Thus, Stroop PD estimates calculated from correct responses made within a series of post hoc deadlines provide a measure of the relative influence of word-reading and color-naming processes on responding over the time course of a trial. 2 . Requiring participants to respond within very short deadlines ( $\leq 400 \mathrm{msec}$ ) can lead to guessing (i.e., the response being given is neither the color nor the name of an item), which raises problems for the Stroop PD procedure (Hillstrom \& Logan, 1997). Because Hillstrom and Logan have shown that guessing is less likely at a $700-\mathrm{msec}$ deadline, we set the deadlines in all of our experiments above $700 \mathrm{msec}$.

3. Advocates of a general slowing explanation for age differences in Stroop interference have suggested that proportional Stroop interference scores should be used as a way to control for differences in baseline speed of responding. However, there is as yet no consensus on whether this is a better measure than the more commonly used comparison of latencies for incongruent and baseline trials.

(Manuscript received October 27, 2003;

revision accepted for publication June 29, 2004.) 